\title{
Reactive distillation: Stepping up to the next level of process intensification
}

DOI:

10.1021/acs.iecr. 8 b05450

\section{Document Version}

Accepted author manuscript

Link to publication record in Manchester Research Explorer

\section{Citation for published version (APA):}

Kiss, A. A., Jobson, M., \& Gao, X. (2018). Reactive distillation: Stepping up to the next level of process intensification. Industrial \& Engineering Chemistry Research. https://doi.org/10.1021/acs.iecr.8b05450

\section{Published in:}

Industrial \& Engineering Chemistry Research

\section{Citing this paper}

Please note that where the full-text provided on Manchester Research Explorer is the Author Accepted Manuscript or Proof version this may differ from the final Published version. If citing, it is advised that you check and use the publisher's definitive version.

\section{General rights}

Copyright and moral rights for the publications made accessible in the Research Explorer are retained by the authors and/or other copyright owners and it is a condition of accessing publications that users recognise and abide by the legal requirements associated with these rights.

\section{Takedown policy}

If you believe that this document breaches copyright please refer to the University of Manchester's Takedown Procedures [http://man.ac.uk/04Y6Bo] or contact uml.scholarlycommunications@manchester.ac.uk providing relevant details, so we can investigate your claim.

\section{OPEN ACCESS}




\title{
Reactive distillation: Stepping up to the next level of process intensification
}

\author{
Anton A. Kiss, ${ }^{\text {a,b* }}$ Megan Jobson, ${ }^{\text {a Xin Gao }}{ }^{\text {a,c }}$ \\ ${ }^{a}$ The University of Manchester, School of Chemical Engineering and Analytical Science, Centre for Process \\ Integration, The Mill, Sackville Street, Manchester M13 9PL, United Kingdom, tony.kiss@manchester.ac.uk \\ ${ }^{b}$ University of Twente, Sustainable Process Technology, PO Box 217, 7500 AE Enschede, The Netherlands \\ ${ }^{c}$ Tianjin University, School of Chemical Engineering and Technology, National Engineering Research Center \\ of Distillation Technology, Collaborative Innovation Center of Chemical Science and Engineering(Tianjin), \\ Tianjin 300072, China
}

\begin{abstract}
Reactive distillation (RD) is an efficient process intensification technique that integrates chemical reaction and distillation in a single apparatus. The process is also known as catalytic distillation when a solid catalyst is used. RD technology has many key advantages such as reduced capital investment and significant energy savings, as it can surpass equilibrium limitations, simplify complex processes, increase product selectivity and improve separation efficiency. However, RD is also constrained by thermodynamic requirements (related to volatility differences and heat of reaction), the need to align the reaction and distillation operating conditions, and the availability of catalysts that are active, selective and with sufficient longevity.

This paper is the first to provide an overview and insights into novel integrated reactive distillation technologies that combine RD principles with other intensified distillation technologies - e.g. dividing-wall column (DWC), cyclic distillation, HiGee distillation, heat-integrated distillation column (HIDiC), and membrane-, microwaveor ultrasound-assisted distillation - potentially leading to the development of new processes and applications.
\end{abstract}

Keywords: hybrid process, dividing-wall column, cyclic distillation, high gravity, heat integration, green energy

\section{Introduction}

Reactive distillation (RD) is one of the best success stories of process intensification technology - developed since the early 1920 s - that already made a strong positive impact in the chemical process industries, and has a great potential for process modularization. Nowadays, RD is considered an established industrial unit operation, being the front-runner in the PI field with more and more applications reported in literature. ${ }^{1-6}$

RD relies on the synergy generated when combining catalyzed reactions and distillation into a single unit. But, as both operations take place in the same unit at the same time, there must be a good match between the operating parameters required for reaction and distillation. ${ }^{7}$ This overlap is usually limited by the properties of the components (e.g. boiling points), catalytic activity and selectivity, and the equipment design among others. Usually this leads to a restricted area in which RD is actually feasible, being a trade-off as shown in Figure $1 .{ }^{4}$ However, this figure does not show the complete picture as there are also other parameters that play a role (e.g.: mass transfer, residence time, reaction rate) and can be altered by using different equipment of operating mode.

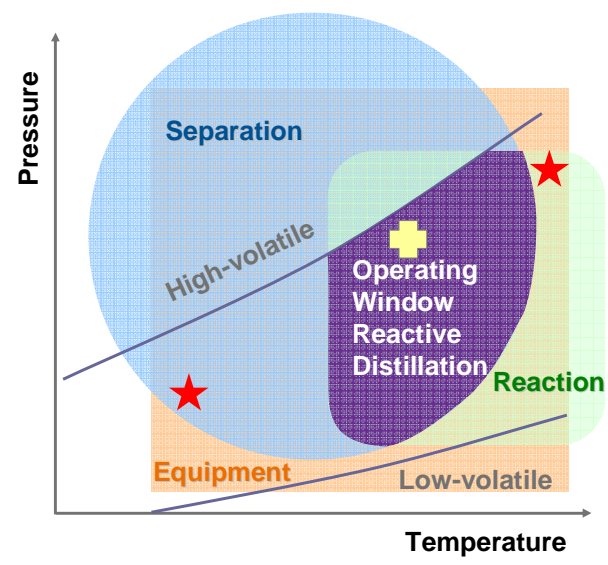

Figure 1: RD requires an overlap of the operating windows for reaction and separation. The star symbols illustrate cases where standalone separation and reaction are preferred, while the plus indicates a match for RD. 
The main research and development (R\&D) steps that are used to develop a RD process are illustrated in Figure $2 .{ }^{8}$ Literature data and rigorous simulations are typically used to guide the conceptual process design and the experimental program, while the lab/pilot-scale experiments serve to validate the simulation model. Afterwards, the experimentally validated model is used for process scale-up, sensitivity studies, optimization, and economic evaluation. The approach aims to reduce the uncertainty and increase the knowledge about the process to allow reliable design and construction of realizable RD processes.

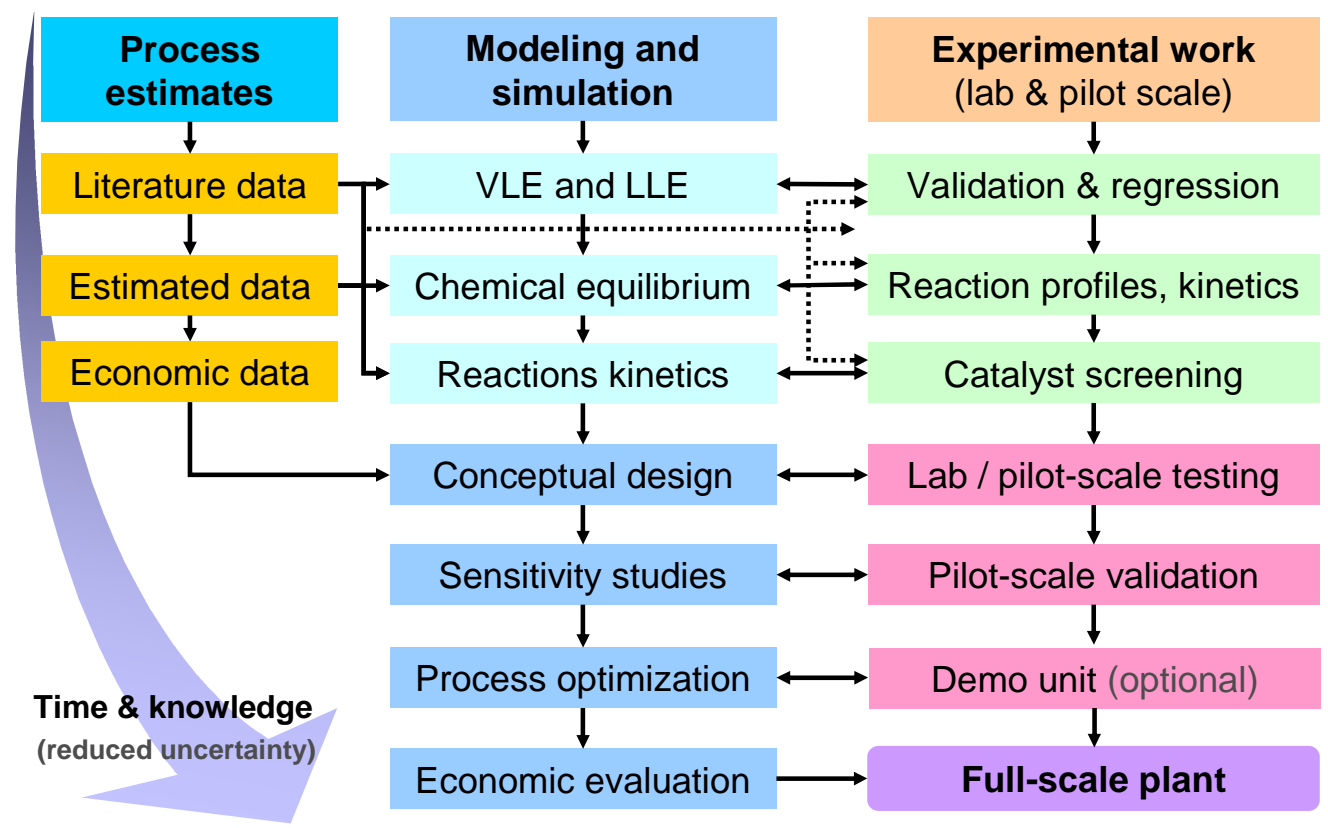

Figure 2: Research \& development steps for a RD process development based on simulation and experiments

Reactive distillation allows chemical reaction and separation to take place simultaneously inside the column, thus providing a valuable synergistic effect that overcomes the equilibrium limitations of many reactions, e.g.: (trans-)esterification, etherification, hydrolysis, (de-)alkylation, (de-)hydration, (de-)hydrogenation, amination, amidation, aldolization, chlorination, condensation, isomerization, dimerization, and oligomerization. ${ }^{9-12}$ RD can be also used for fast reactions where the high concentration of one of the products or reactants may lead to undesired side reactions, hence the strong need to reduce their concentration in the reacting phase to minimal levels in order to hinder the undesired side reactions. RD can be also used to separate azeotropes, based on the difference between the reaction rates of the substances forming the azeotrope with another reactant. For instance, one compound from an azeotrope could be reacted to form products that are easier to separate (by distillation) from the other substances in the azeotrope. Furthermore, the products could undergo a reversible reaction to form the original substance using a RD process to achieve the desired separation of the azeotrope mixtures. ${ }^{13-16}$

In spite of the remarkable developments during the past decades, the potential of RD technology has not been fully tapped yet, and there is still undergoing research to improve it further by various process intensification means: e.g. use of dividing-walls, cyclic operation, internally heat integration, high-gravity fields, or coupling RD with other operations (membrane separations), or use of alternative energy (ultrasounds or microwaves). This review paper - invited for the special issue of Industrial \& Engineering Chemistry Research about Frameworks for Process Intensification and Modularization - aims to provide an insightful overview of recent novel $\mathrm{RD}$ technologies that combine the principles of reactive distillation with other intensified technologies, leading to new hybrid processes (amenable to modular manufacturing) such as:

- Reactive dividing-wall columns (R-DWC) - allows the separation and recycle of a reactant excess, thus sparing the need for an additional distillation unit.

- Reactive cyclic distillation or catalytic cyclic distillation (CCD) - offers larger liquid holdups and residence time, making it suitable for slow reactions.

- Reactive (internally) heat-integrated distillation column (R-HIDiC) - provides different operating pressure and temperature for reaction and separation in the stripping and rectifying sections. 
- Reactive HiGee distillation (R-HiGee) - works at high gravitational forces that dramatically enhance the mass transfer, although at the expense of reducing the residence time.

- Membrane-assisted reactive distillation (M-RD) - allows additional separations to take place next to RD.

- Microwave-assisted reactive distillation (MW-RD) - can provide targeted energy input (local heating).

- Ultrasound-assisted reactive distillation (US-RD) - improves mass transfer and rates by sonication.

A comparison with classical RD processes is made, where strengths and weaknesses are analyzed, considering process synthesis and design, controllability and operability, energy efficiency, key benefits and limitations, and the potential for practical adoption of these technologies by the chemical industry. We also highlight the most promising of these RD technologies, as well as the research challenges and directions of development that lie ahead for industrial adoption.

\section{Classic reactive distillation}

The literature covers a large range of topics about RD technology, including: thermodynamics, feasibility and applicability, conceptual design, modeling and process simulations, optimal design, design and control, process configurations, process scale-up, green engineering aspects, industrial perspectives and novel applications. ${ }^{5}$ The main configurations of classic RD processes are illustrated in Figure 3, ranging from a conventional setup (for quaternary reactive systems) to azeotropic reactive distillation (column coupled with a decanter to separate the heterogeneous azeotrope), and RD with pre-reactors, ${ }^{17}$ and/or side-reactors to increase the residence time. ${ }^{10}$

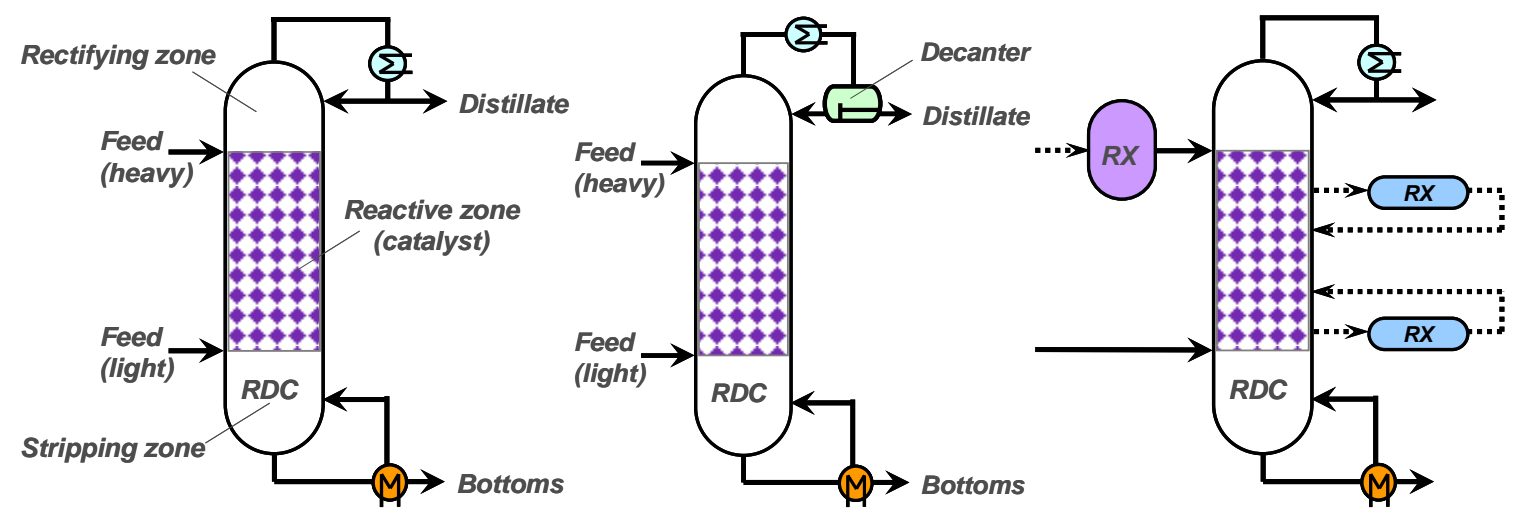

Figure 3: Configurations of reactive distillation (RD) processes: classical RD column (left), azeotropic RD (middle), RD with optional (dashed line) pre- and/or side-reactors (RX) that can increase conversion (right).

From a catalysis viewpoint, several possible situations are envisaged: no catalyst, homogeneous catalyst, or heterogeneous catalyst. In practice, this means that the catalyst is allowed to leave the RD column in one of the product streams; or it is neutralized and separated as salt waste; or it is separated and recycled; or no catalyst separation or recovery is required. ${ }^{4}$ A particular case of catalysis is the use of immobilized enzymes that allow new possibilities for the application of biocatalysts in organic synthesis, for example in the production of chiral compounds.

Enzymatic Reactive Distillation (ERD) is a bio-reactive process, in which enzymes, immobilized on the internal surface of a column, help to overcome chemical reaction and phase equilibrium limitations. ${ }^{18-21}$ A biocatalytic hydrophobic silica coating for commercial structured packing can be used to enable enzymatic reactions in RD columns. Such a continuous ERD process was developed and proven experimentally at pilot scale. However, ERD processes are somewhat hindered by to the limited temperature interval in which the enzymes are active, hence the operating window of the ERD process is narrow in terms of temperature and pressure. ${ }^{18}$

\section{Advanced reactive distillation}

Taking reactive distillation to the next level of process intensification requires more advanced configurations, which extend the range (and overlap) of operating conditions beyond those applicable to classical RD. ${ }^{22}$ Other variations of RD may include for example: integration with other PI technologies, use of different operation mode, or membrane- or microwave- or ultrasound-assisted reactive distillation for further energy savings, high efficiency and environmental friendliness. ${ }^{23-25}$ 


\subsection{Reactive dividing-wall columns}

RD in a dividing wall column (DWC) was a logical next step waiting to be developed in academia and applied industrially. Literature reports range from rate-based modeling and simulation of R-DWC processes, ${ }^{26}$ to broad analysis of the reactive dividing-wall column, its minimum energy demand and the potential for energy savings, ${ }^{27}$ and more recently a comprehensive review on R-DWC. ${ }^{28}$ The R-DWC has been modeled using ratebased approaches and the performance of R-DWC units has been theoretically studied for different chemical systems. Some research groups investigated R-DWC using standard routines available in commercial process simulators (e.g. Aspen Plus), but experimental investigations of R-DWC configurations are still very scarce. The advantages demonstrated by this highly integrated process, in both modeling and experimental studies are: high conversion, increased selectivity and product purity, significant energy and cost savings.

Figure 4 illustrates the typical configuration of a generic R-DWC, as well as an application to the dimethyl ether (DME) process. ${ }^{10} \mathrm{R}$-DWC applications have been reported (mostly as simulation studies) for the production of various chemicals e.g. methyl acetate, ${ }^{29,30}$ ethyl acetate, ${ }^{31,32}$ dimethyl ether, ${ }^{33}$ fatty acid methyl esters (FAME), ${ }^{34}$ biodiesel, ${ }^{35,36}$ diethyl carbonate, ${ }^{37} \mathrm{n}$-propyl propionate, ${ }^{38}$ and other industrial applications. ${ }^{39}$
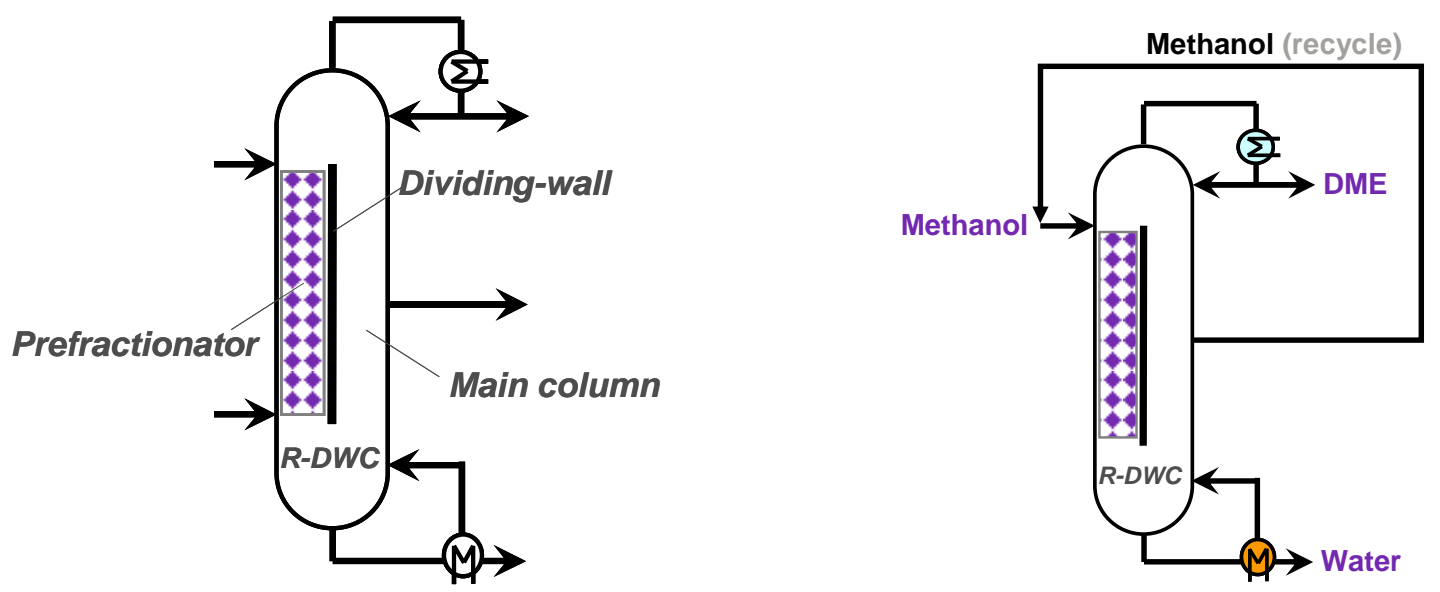

Figure 4: Reactive dividing-wall column: generic configuration (left), specific setup for DME synthesis (right)

R-DWC technology has been an active area of research during the past decade, with many studies concluding that the technology is industrially feasible and ready for implementation at commercial scales. The main challenges to the commercialization of R-DWC are the lack of experimental results (currently limited to only 5 chemical systems, 2 lab-scale and 2 industrial scale units), uncertainties in R-DWC modeling and simulation, lack of demonstration of (complex) control schemes (e.g. model predictive control), need for improvement of dynamic models and shortcut design. Nonetheless, R-DWC technology can add significant value to new chemical processes, with a strong potential to improve production yields, to save $15-75 \%$ in energy usage and over $20 \%$ in capital cost, as compared to conventional processes. ${ }^{28}$ The design and control of R-DWC can draw on the extensive experience of RD and DWC, respectively. The key limitations of R-DWC relate to: catalyst formulation, hold-up \& residence time, pressure drop \& flooding, and the need for equal pressure drop on the two sides of the dividing wall. The main potential applications are reversible reactions where the components have suitable boiling point characteristics (i.e. that allow separation while also being suitable for the reaction).

\subsection{Catalytic cyclic distillation}

Cyclic distillation is as a new contender in fluid separations, providing an innovative way of creating contact between the liquid and vapor phases. ${ }^{10}$ Unlike conventional operation, cyclic distillation uses separate phase movement (SPM) that can be achieved with technology-specific internals and a periodic operation mode ${ }^{40,41}$ One operating cycle consists of two key parts: a vapor flow period (when the thrust of rising vapor prevents liquid downflow) followed by a liquid flow period (when the liquid flows down the column, dropping by gravity from one tray to the tray below). This cyclic mode of operation leads to key advantages, compared to conventional trayed columns: high throughput and equipment productivity, high separation efficiencies (140$200 \%$ Murphree efficiency), reduced energy requirements (20-35\% savings), and increased quality of the products. The pilot scale implementation of the cyclic distillation technology available at Maleta Cyclic 
Distillation (www.maletacd.com) is expected to be valuable for demonstration of technology-readiness.

Adding a catalyst on the trays leads to catalytic cyclic distillation (CCD) that is a novel process intensification approach in reactive separations. ${ }^{42}$ Figure 5 illustrates the typical internals used for cyclic distillation. Such a setup allows control of the amount of liquid on the tray, and thus the reaction time. As the liquid holdup and the amount of catalyst per tray can be significantly greater than in conventional RD systems, applications to slower reactions become feasible as well, thus extending the range of applicability of RD.

In terms of design and control, dynamic models are needed, where multiple degrees of freedom require optimization. Key challenges include: moving parts (especially in the presence of catalyst particles); obtaining good mixing and turbulence in the liquid phase, to enhance the reaction, without damaging the catalyst particles. Adding structured catalytic packing or catalytic internals on the tray may overcome this challenge. As with RD technology, $\mathrm{CCD}$ is limited to liquid-phase reactions (i.e. reactions taking place at relatively low temperatures). Nonetheless, CCD enables good utilization of the column shell (as there is a high ratio of catalyst volume and liquid hold-up to the space available for vapor flow); potentially CCD has a good range of application (e.g. for slower reactions). However, there is a need for development and validation of sophisticated process modeling approaches for design, control and optimization purposes.
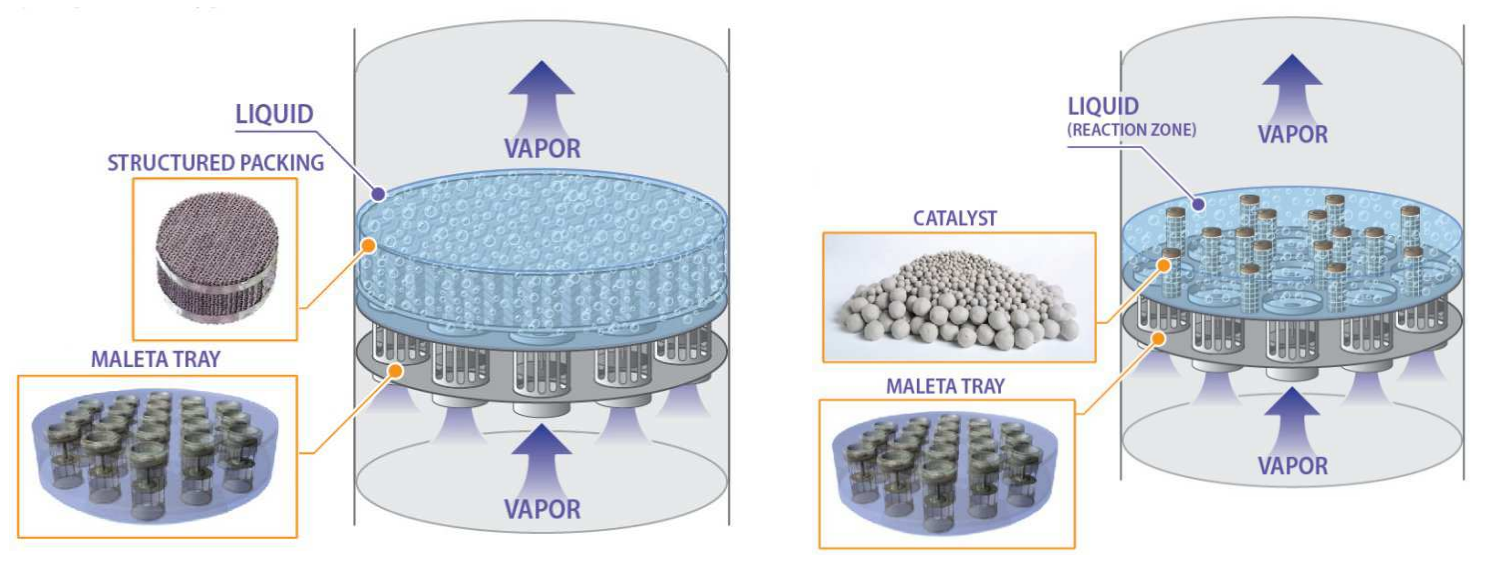

Figure 5: Schematics of cyclic distillation internals: (left) Maleta trays and packing; (right) Maleta trays with solid catalyst - photos courtesy of Maleta Cyclic Distillation (www.maletacd.com).

\subsection{Reactive heat-integrated distillation column}

The heat integrated distillation column (HIDiC) is a radical approach for applying heat pumping to assist distillation. The technology makes use of internal heat integration: the whole rectifying section of a column is the heat source, while the stripping part acts as a heat sink. ${ }^{43-45}$ Heat is transferred from the rectifying section (operated at high pressure) to the stripping section. The heat required for evaporation in the stripping section is thus obtained from the rectifying section, reducing the heat duty of the reboiler (but shaftwork is needed for compression). Overall, HIDiC can achieve primary energy savings (and associated $\mathrm{CO}_{2}$ emissions) of 70$90 \% .^{46,47}$ The industrial implementation of HIDiC (SuperHIDiC by Toyo Engineering Corporation: www.toyoeng.com/jp/en/products/environment/superhidic/) is serving as a valuable demonstrator that could significantly increase the confidence of industry in the HIDiC technology. 45

Combining HIDiC with RD in a single unit leads to a reactive system (R-HIDiC) with potential for industrial applications. Figure 6 illustrates the concept of reactive HIDiC. Savings would be expected in capital and energy costs. In addition, R-HIDiC has potential to be applied to azeotrope-forming mixtures where the reaction can consume the azeotropes. The simulation of this new technology was reported for tert-amyl methyl ether production, ${ }^{48-50}$ ethyl acetate synthesis, ${ }^{51,52}$ and EO hydration to ethylene glycol. ${ }^{53}$ However, to date, only simulation studies have been reported and experimental validation of the process concept is lacking.

Design and control can benefit in practice from the 'simplicity' of the SuperHIDiC concept using two discrete heat exchangers, which is a good compromise that provides high energy savings at low investment costs, in an operable configuration. The outlook for R-HIDiC is positive, as the high energy savings of HIDiC provide strong incentives - although the initial R-HIDiC studies showed only up to $22 \%$ savings, compared to classical $\mathrm{RD}$ processes. However, the range of applicability (beneficial to equilibrium-limited reactions) is likely to be narrower than that for conventional RD, i.e. close-boiling mixtures (to avoid high pressure difference between 
the rectifying and stripping sections). Moreover, the boiling points difference and the compression ratio are key limiting factors on the applicability of R-HIDiC to various reactive systems.
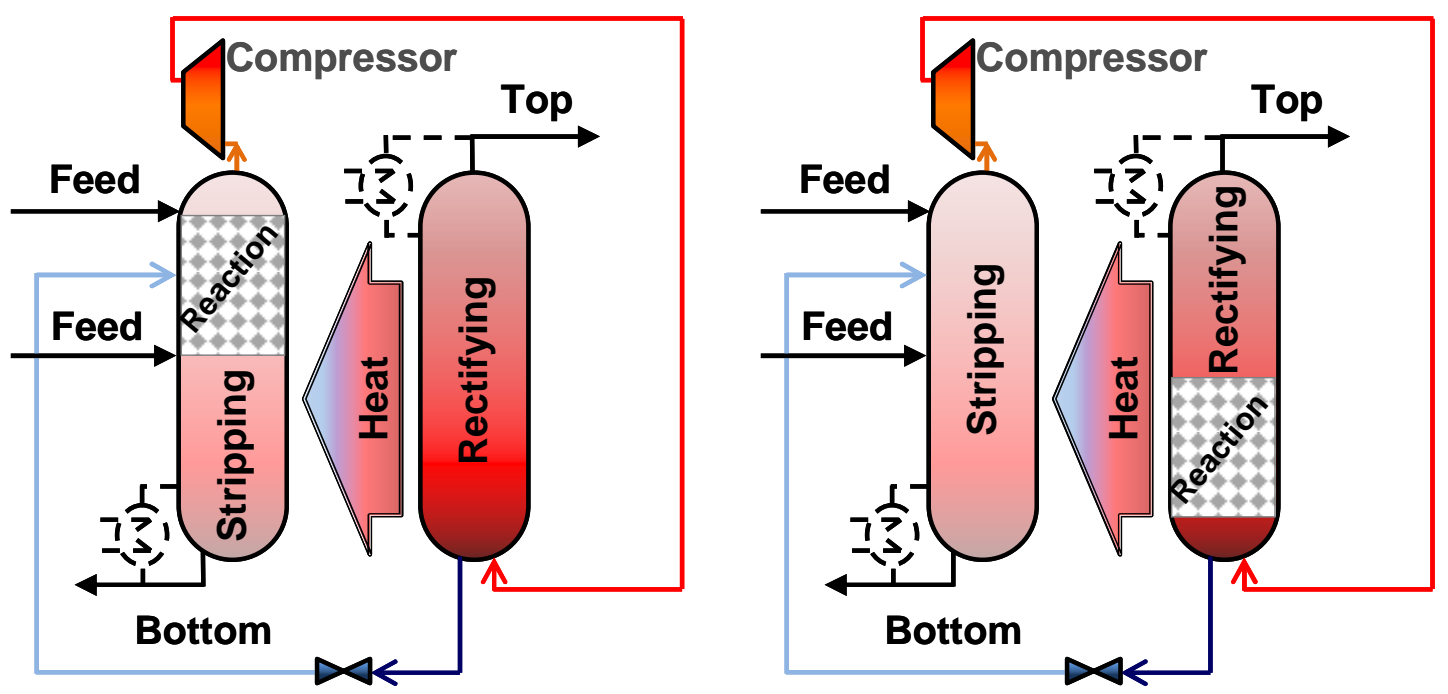

Figure 6: Reactive HiDIC configurations with the reactive zone located in the stripping or rectifying section.

\subsection{Reactive HiGee distillation (R-HiGee)}

High-gravity (HiGee) technology replaces the usual gravitational field by a centrifugal field achieved in a specially shaped rotating device. The high-gravity field (100-1000 $\mathrm{g}$ ) shifts the flooding limit and allows the use of dense packing materials with a high interfacial area. For rotating packed beds (as illustrated in Figure 7), HETP values as low as 2 to $8 \mathrm{~cm}$ have been reported, while for rotating zig-zag beds (RZB), a volume reduction of a factor of 4 to 7 is claimed for certain distillations (compared to conventional columns) thus enabling process modularization. ${ }^{54}$ Furthermore, one could also add a catalyst to convert the system into a reactive HiGee distillation. The two-stage counter-current rotating packed bed (RPB, an upgraded version of RZB) combines the benefits of the RZB with the capability to use packing and it has been assessed (together with conventional $\mathrm{RPB}$ ) to be the most appropriate equipment to perform RD among all HiGee contactors available. ${ }^{54}$
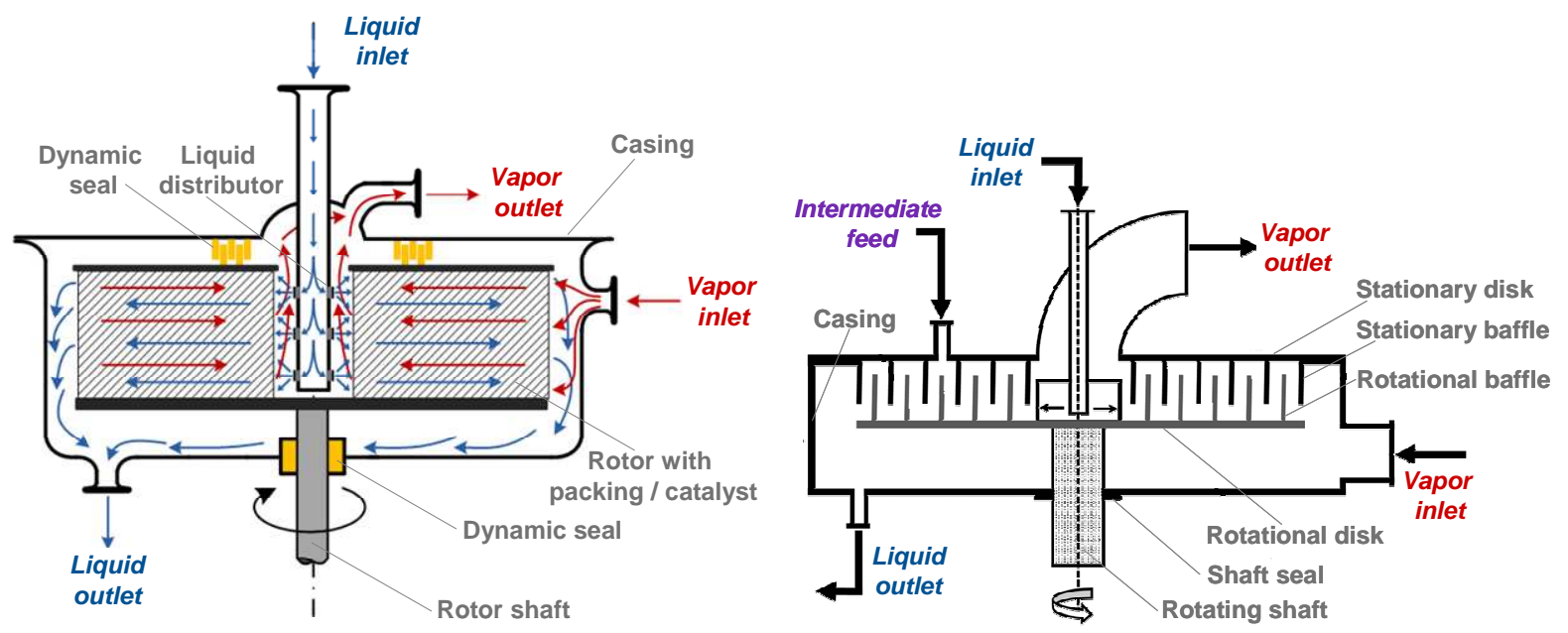

Figure 7: Rotating Packed-Bed (left) ${ }^{11}$ and Rotating Zig-zag Bed (right) ${ }^{54}$ for (reactive) HiGee distillation.

As early as 1999, Dow Chemicals successfully introduced the reactive stripping of hypochlorous acid as one of the first commercial applications of RPBs. ${ }^{54} \mathrm{~A}$ model of a novel reactive HiGee distillation process has been developed, and then applied for analysis and optimization of a reactive HiGee stripper-membrane process for methyl lactate hydrolysis. ${ }^{55,56}$ Solid-catalyzed reactive stripping has also been reported in a simulation study 
about the production of octyl-hexanoate with simultaneous water removal from the reaction zone of an RPB. ${ }^{57}$ While few studies have included solid catalysts in the (wire mesh) packing, published results showed the potential of HiGee for solid-catalyzed gas-liquid reactions and even for reactive distillation. ${ }^{58,59}$ This potential mainly results from the intensified gas-liquid mass transfer rates and the good catalyst wetting at high gravity. But prolonged operation at high gravity also results in erosion of the catalyst entrapped in the internals (e.g. wire mesh). An important limitation is the very low liquid holdup of RPBs, and the correspondingly low residence times that limit application of RPBs to reactive systems with very high reaction rates. Therefore, reactive HiGee technologies need more research to enhance packing design in order to achieve higher liquid-phase residence times and thus to extend the range of applicability of RPBs. For now, the range of applicability is limited to liquid-phase reactions only and includes fast reactions with competing serial reactions, to achieve enhanced selectivity and ensure low yield losses. ${ }^{54}$

\subsection{Membrane-assisted reactive distillation}

Membrane-assisted reactive distillation (M-RD) has a high potential for process intensification, as underlined in a study about recent developments and challenges of M-RD. ${ }^{23}$ Although membrane-assisted separations are sparsely applied in industry - due to their complexity in design and operation - significant progress has been made during the past decades in terms of design tools and experimental validation.

An industrial team from Sulzer ChemTech reported a process for the continuous production of fatty acid esters via a membrane-assisted reactive distillation process - see Figure 8 (left). ${ }^{60}$ In one example, the esterification of palmitic acid (PA) with isopropyl alcohol (IPA) is described. The water / IPA mixture that leaves the top of the $\mathrm{RD}$ column is treated in a membrane system, in which water is pervaporated through the membrane while the dry IPA can be recycled. Similar processes are possible for other esterification reactions of fatty acids. ${ }^{60}$

A similar membrane assisted RD process was developed for the production of n-butyl acetate by transesterification of methyl acetate with n-butanol. ${ }^{61}$ A strongly acidic ion-exchange resin (Amberlyst 15) was used as catalyst in the RD column which was equipped with structured catalytic packing Sulzer Katapak. A Pervap 2255 membrane was used for the pervaporation to separate the methanol - methyl acetate mixture obtained as the distillate stream of the RD column. The experimental results showed a good agreement with the simulations. The etherification of tert-amyl alcohol with ethanol has been evaluated by simulation and experimentally in a RD column which had a zeolite NaA membrane tube inserted - leading to a $10 \%$ increase in the yield of tertamyl ethyl ether. ${ }^{62}$ In spite of the multiple assumptions made in the models, there was a good agreement between the experimental and the simulation results.

Buchaly et al. ${ }^{63}$ investigated experimentally, at pilot scale, a novel M-RD process to produce propyl propionate by the esterification of propionic acid with n-propanol. Vapor permeation was applied to separate water byproduct from a heterogeneous, low-boiling ternary azeotrope (between n-propanol, propyl propionate and water). Similarly, Lv et al. ${ }^{64}$ studied experimentally, at pilot scale, another M-RD process for the esterification of acetic acid with ethanol to produce ethyl acetate and water. In this case, a pervaporation membrane was connected to the reboiler to separate water from the ethyl acetate/water mixture.

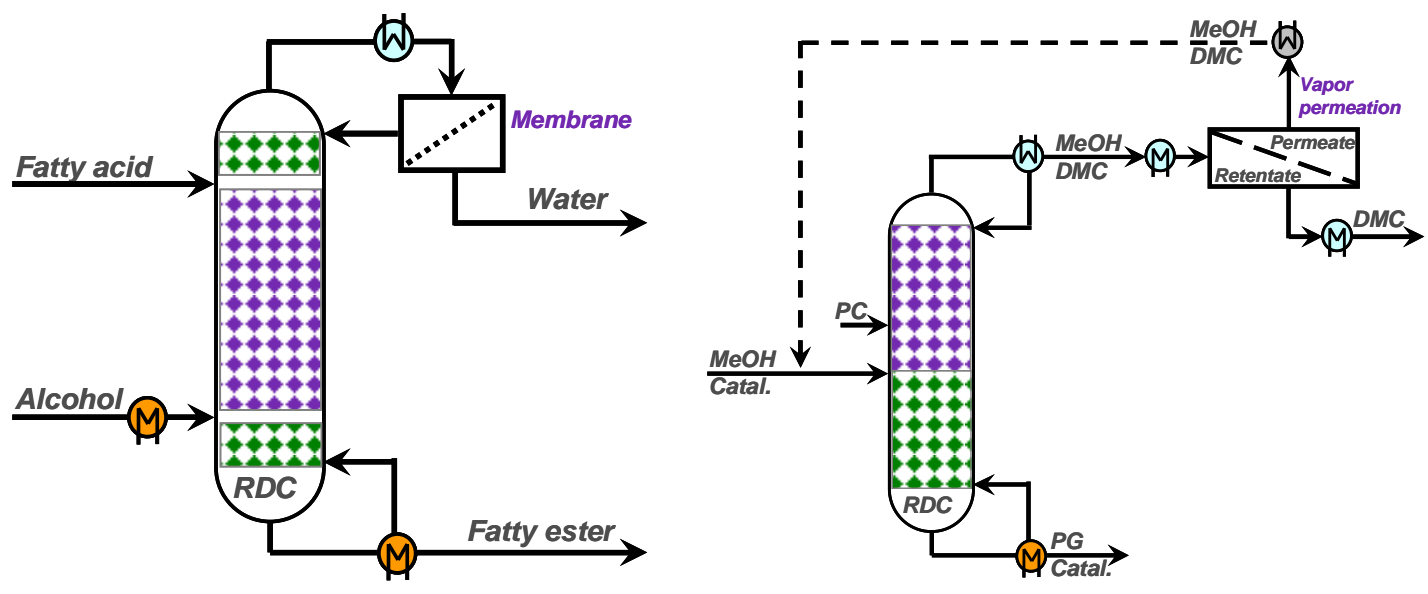

Figure 8: Membrane-assisted reactive distillation processes for fatty esters (left) and DMC synthesis (right) 
The synthesis of dimethyl carbonate (DMC) and propylene glycol (PG) - by trans-esterification of propylene carbonate with methanol - in a new M-RD process has been reported. ${ }^{65}$ Conversion is limited by chemical equilibrium, while the purification of DMC is hindered by the formation of an azeotrope with methanol. RD was used to overcome the limitation of the chemical equilibrium, whereas vapor permeation was used to separate the azeotrope - as shown in Figure 8 (right). A detailed pilot-scale experimental study was performed to quantify the synergistic effects between both unit operations, and the experimental results were applied to validate the model that was used afterwards to analyze the process.

Overall, the M-RD process is similar to an azeotropic RD system with the main difference that it uses a membrane instead of a decanter for separation thus not being limited to systems forming two-liquid phases. Yet, the use of membranes also brings into the M-RD process their own advantages (e.g. cheap separation without evaporation) and drawbacks (e.g. fouling, need for replacement). ${ }^{66}$ The combination of membrane and RD in one unit and/or series arrangements has excellent potential to further intensify the performance of RD, e. $g$. for the production esters and ethers (e.g. where the timely removal of water by-product is crucial).

\subsection{Microwave-assisted reactive distillation}

Microwave-assisted distillation is a combination of microwave (MW) heating (a form of electromagnetic radiation with wavelengths ranging from 1 meter to 1 millimeter) and distillation in the same apparatus, where microwave is used as an alternative energy source. Selective absorption of energy or use of energy only where is needed (e.g. relative to conventional heating, partly because energy is not used to heat the equipment), reduction of greenhouse gas emissions, and high product quality are among the key advantages of microwave heating. For distillation processes, it has been reported that microwave might enhance the concentration of polar components in the vapor phase, and may even influence the boiling point and composition of a mixture comprising polar and non-polar species, where these changes may further promote the distillation process. ${ }^{67-69}$ Microwave irradiation into reactive distillation column could enhance the reaction rate for a slow reaction and simultaneously improve the efficiency of the distillation process. Gao et al. ${ }^{70}$ investigated experimentally in a DN 100 pilot-scale a continuous MW-RD process developed for the synthesis of di-2-ethylhexyl phthalate (as illustrated in Figure 9).

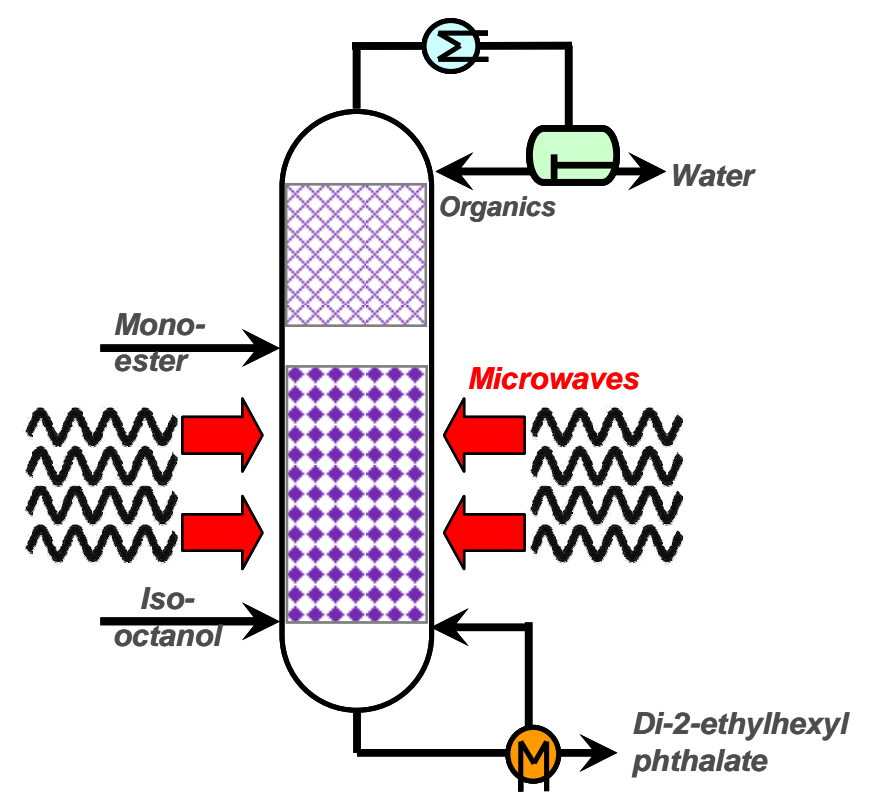

Figure 9: Microwave-assisted reactive distillation. ${ }^{70}$

However, only few studies on microwave-assisted reactive distillation have been reported, and the underlying physical principles are not yet well understood. For instance, Altman et al. ${ }^{71}$ carried out separate experiments on microwave reaction and microwave distillation for synthesis of n-propyl propionate; they concluded that microwaves could promote the reactive distillation process. Similarly, bench-scale studies of Werth et al. ${ }^{24}$ also considered the individual effects of MW on various reactions and phase equilibrium. In contrast to Altman et al. ${ }^{71}$ the study of Werth et al. ${ }^{24}$ found no evidence to suggest that microwave irradiation influences reaction or 
separation in a reactive distillation process. Later, batch experimental studies of microwave-assisted reactive distillation of Ding et al. ${ }^{72}$ demonstrated that the performance of RD for synthesis of ethyl acetate could indeed be enhanced in the presence of microwaves, compared to using conventional heating. Recently, a continuous pilot-scale MW-RD column has been applied for the synthesis of di-2-ethylhexyl phthalate, ${ }^{70}$ in which a model of the MW-RD process was developed and applied for analysis of the process.

The main potential applications for MW-RD are reactions where the chemical products have high dielectric constant characteristics that allow the products to absorb the MW and separate quickly from reactive system. Hence the applicability of MW-RD is severely limited to the chemical systems on which MW have an influence (besides local heating), and this is still a debated topic as the underlying science is not fully understood. Currently, the lack of fully mature devices to facilitate the microwave use at large scale and to mitigate the MW penetration depth issue is a key barrier to commercial uptake of MW-RD technology.

\subsection{Ultrasound-assisted reactive distillation}

The field of sonochemistry has established that ultrasound (US) creates acoustic cavitation in liquids (i.e. the formation, growth, and implosive collapse of bubbles), resulting in the initiation or enhancement of the chemical activity in the solution. Benefits of using US in other operations (e.g. liquid-liquid extraction, crystallization, reactive distillation) include: high energy-density source (of lower volume), operational flexibility, fast response time to variations in inlet conditions, and low operating costs. ${ }^{73}$ However, due to the technical and operational limitations to scale up US systems, the transition from the lab to industrial scale has been hindered so far.

Activation of enzymes by ultrasound leads to ultrasound-assisted ERD (US-ERD), with concomitant benefits, including reduced energy (utility) requirements, related to significantly increased reaction rates. Enzymatic reactions are often limited in conversion and are rather slow but can be intensified by using ultrasound (US) which leads to increased reaction rates, while distillation increases conversion via in-situ product removal. The beneficial effects of US on the rate of the enzymatic reaction of the trans-esterification of ethyl butyrate have recently been reported, ${ }^{18}$ e.g. $50 \%$ increase in the reaction rate, compared to the unsonicated system. Wierschem et al. ${ }^{18}$ designed and optimized a US-ERD process for the synthesis of butyl butyrate $(10,000 \mathrm{t}$ per year, $99 \mathrm{wt} \%$ purity) to minimize the total annual costs (process shown in Figure 10). The techno-economic evaluation found that the US-ERD process and the ERD process have very similar costs. While installation costs of the US equipment are high, they are compensated by the reduced height of the ERD column associated with the reduced height of its reactive section. Cost advantages are expected if a sufficiently high increase in the reaction rates is obtained by applying US, such that the additional costs required for US equipment are overcompensated by the process improvements obtained by the use of US. ${ }^{73}$ For now, the application of US-RD remains limited due to the lack of large scale US devices, although a roadmap has been proposed for its industrial implementation. ${ }^{73}$

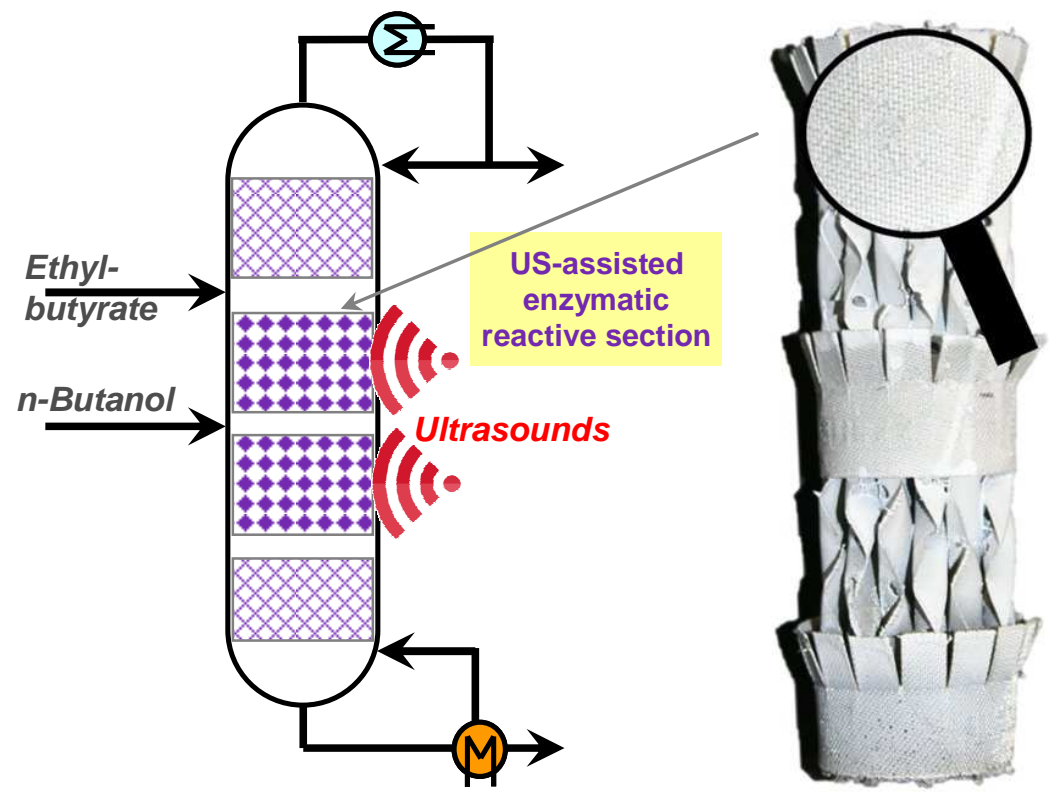

Figure 10: US-ERD process using enzyme coated packing placed in a reactive section. 


\section{Comparison of reactive distillation processes}

Table 1 provides a convenient comparison of the RD processes discussed in the previous sections. This analysis is based on industrial and academic experience, as well as on the information available in literature. This summary captures only qualitatively the current situation, while research, development and novel applications in the coming years are expected to provide additional understanding and insights.

Table 1. Comparison of RD processes combined with other process intensification technologies

\begin{tabular}{|c|c|c|c|c|c|c|c|}
\hline & RD & R-DWC & CCD & R-HIDiC & R-HiGee & MW-RD & US-RD \\
\hline $\begin{array}{l}\text { Process design \& simulation } \\
\text { (availability of methods \& tools) }\end{array}$ & +++ & +++ & ++ & ++ & + & ++ & ++ \\
\hline $\begin{array}{l}\text { Process dynamics and control } \\
\text { (availability of methods \& tools) }\end{array}$ & +++ & ++ & ++ & + & + & ++ & ++ \\
\hline $\begin{array}{l}\text { Practical challenges } \\
\text { (ease of implementation) }\end{array}$ & +++ & ++ & ++ & + & + & ++ & ++ \\
\hline $\begin{array}{l}\text { Range of applicability } \\
\text { (variety of chemical reactions) }\end{array}$ & +++ & ++ & ++ & + & + & +++ & ++ \\
\hline $\begin{array}{l}\text { Technology-readiness } \\
\text { (pilot \& industrial experience) }\end{array}$ & +++ & ++ & + & $\mathrm{n} / \mathrm{a}$ & $\mathrm{n} / \mathrm{a}$ & + & + \\
\hline $\begin{array}{l}\text { Energy savings } \\
\text { (compared to classical processes) }\end{array}$ & $15-80 \%$ & $15-75 \%$ & $20-35 \%$ & $50-90 \%$ & $\mathrm{n} / \mathrm{a}$ & $5-25 \%$ & $5-25 \%$ \\
\hline $\begin{array}{l}\text { Capital savings } \\
\text { (compared to classical processes) }\end{array}$ & +++ & +++ & +++ & $\mathrm{n} / \mathrm{a}$ & +++ & $\mathrm{n} / \mathrm{a}$ & $\mathrm{n} / \mathrm{a}$ \\
\hline
\end{tabular}

While all these new RD technologies are promising, they are in different stages of development, with various niche applications typically driving the research. Especially R-DWC (building on the success of DWC) and CCD (pushing cyclic distillation further) have high potential for industrial implementation. In principle, R$\mathrm{HIDiC}$ is also promising but has yet to build on the success of SuperHIDiC for industrial applications. Reactive HiGee could drastically reduce equipment sizes, but it does not offer any significant energy savings (on the contrary, it uses additional electricity to drive the rotating equipment) and its range of applicability is limited to fast reactions. Membrane-assisted RD is analogous to an azeotropic RD process, where the decanter (used for liquid-liquid splitting) is replaced by a membrane separation that is able to separate components from a singlephase mixture. The use of alternative forms of energy in MW-RD and US-RD has good potential to extend the range of applications for reactive distillation, but a deeper understanding is strongly needed regarding the mechanisms by which MW irradiation and/or US affect both the reaction and separation mechanisms.

Table 2 provides an overview of the industrial and research applications reported in the literature (as detailed in the previous sections) for these enhanced processes combining RD with other PI technologies.

Table 2. Applications of RD processes combined with other process intensification technologies

\begin{tabular}{|c|c|}
\hline Technology & Applications \\
\hline Reactive distillation & $\begin{array}{l}\text { methyl acetate, methyl tert-butyl ether (MTBE), ethyl tert-butyl ether (ETBE), } \\
\text { tert-amyl methyl ether (TAME), cumene, ethyl benzene, fatty acid esters, } \\
\text { polyesters, (metha)crylic esters, dimethyl ether, natural benzaldehyde, etc. }\end{array}$ \\
\hline Reactive DWC & $\begin{array}{l}\text { methyl acetate, ethyl acetate, dimethyl ether, fatty acid methyl esters, diethyl } \\
\text { carbonate, n-propyl propionate, undisclosed industrial systems }\end{array}$ \\
\hline Catalytic cyclic distillation & dimethyl ether \\
\hline Reactive HIDiC & tert-amyl methyl ether, ethyl acetate, ethylene glycol \\
\hline Reactive HiGee & $\begin{array}{l}\text { hypochlorous acid, fatty acid methyl esters, octyl-hexanoate, methyl lactate } \\
\text { hydrolysis }\end{array}$ \\
\hline Membrane assisted RD & $\begin{array}{l}\text { fatty acid esters (isopropyl palmitate), n-butyl acetate, tert-amyl ethyl ether, } \\
\text { propyl propionate, ethyl acetate, dimethyl carbonate (DMC) }\end{array}$ \\
\hline MW assisted RD & di-2-ethylhexyl phthalate, n-propyl propionate, ethyl acetate \\
\hline US assisted RD & butyl butyrate synthesis \\
\hline
\end{tabular}


Enhancing reactive distillation technology with additional process intensification techniques opens new avenues for process developments and applications especially in the specialty and fine chemicals sectors, for example by using modular manufacturing. ${ }^{74}$

Future research on integrating RD with other technologies should address several aspects. In terms of theoretical research, the mechanism of effectively coupling the chemical reactions and mass transfer for separation is a key issue, especially considering the interaction of RD with other intensification technologies. While process design, optimization and steady-state simulations of RD are relatively mature, studies of the RD dynamic behavior and development of appropriate control strategies, with a focus on methods for simultaneous design and control, are also required. For the development of catalytic distillation, internals for various new RD technologies, the development of suitable catalytic internals (with supported catalysts) - and perhaps even re-inventing the trays / internals of RD - is a key barrier to practical industrial application.

\section{Conclusions}

Novel RD technologies that combine the principles of RD with other intensified distillation technologies - such as dividing-wall column, cyclic distillation, HiGee separation, HIDiC, or assisted by membranes, MW or US can take reactive distillation to the next level of intensification, leading to promising new RD processes for resource-, energy- and capital-efficient production of chemicals. The potential benefit offered by these novel intensified technologies is significant and motivates accelerated research efforts, especially experimental and pilot-scale studies, as well as advanced dynamic and/or rate-based modeling techniques and methodologies to optimize process design and control. Furthermore, there is a need for scientific research to really understand the fundamental phenomena by which microwave irradiation and/or ultrasound affect the chemical undergoing reaction and/or distillation.

\section{Acknowledgments}

A. A. Kiss gratefully acknowledges the Royal Society Wolfson Research Merit Award. X. Gao thanks the China Scholarship Council (No. 201706255020) for his academic visiting fellowship in the UK, and the National Key Research and Development Program of China (2018YFB0604905). The authors also thank the reviewers for their insightful comments and suggestions.

\section{References}

(1) Harmsen, G. J.; Reactive distillation: The front-runner of industrial process intensification: A full review of commercial applications, research, scale-up, design and operation, Chem. Eng. Process., 2007, 46, 774-780.

(2) Kiss, A. A.; Process intensification: Industrial applications, in Segovia-Hernandez, J. G.; Bonilla-Petriciolet A. (Eds); Process intensification in chemical engineering: Design, optimization and control, Springer International Publishing, 2016.

(3) Kiss, A. A.; Process intensification for reactive distillation, in Rong, B-G. (Ed); Process synthesis and process intensification: Methodological approaches, de Gruyter, 2017.

(4) Wierschem, M.; Gorak, A.; Reactive distillation, Elsevier Ref. Module Chem. Mol. Sci. Chem. Eng., 2018, DOI: 10.1016/B978-0-12-409547-2.14066-1

(5) Kiss, A. A.; Novel catalytic reactive distillation processes for a sustainable chemical industry, Top. Catal., 2019, Article in press, DOI: $10.1007 / \mathrm{s} 11244-018-1052-9$

(6) Gupta, R.; Shah, S.; Dubey, S.; Review on reactive distillation and recent applications, Imp. J. Inter. Res., 2016, 2(12), 314-317.

(7) Schembecker, G.; Tlatlik, S.; Process synthesis for reactive separations, Chem. Eng. Process., 2003, 42, 179-189.

(8) Li, H.; Meng, Y.; Shu, C.; Li, X.; Kiss, A. A.; Gao, X.; Innovative reactive distillation process for the sustainable synthesis of natural benzaldehyde, ACS Sust. Chem. Eng., 2018, 6, 14114-14124.

(9) Sundmacher, K.; Kienle, A.; Reactive distillation: Status and future directions, Wiley, 2003.

(10) Kiss, A. A.; Advanced Distillation Technologies - Design, Control and Applications, Wiley-Blackwell, Chichester, UK, 2013. 
(11) Kiss, A. A.; Distillation technology - Still young and full of breakthrough opportunities, J. Chem. Technol. Biot., 2014, 89, 479-498.

(12) Kiss, A. A.; Lange, J. P.; Schuur, B.; Brilman, D. W. F.; van der Ham, A. G. J.; Kersten, S. R. A.; Separation technology - Making a difference in biorefineries, Biomass Bioenergy, 2016, 95, 296-309.

(13) Li, H.; Huang, W. J.; Li, X. G.; Gao, X.; Application of aldolization reaction in separating the mixture of ethylene glycol and 1,2-butanediol: Thermodynamics and new separation process. Ind. Eng. Chem. Res., 2016, 55(37), 9994-10003.

(14) Li, H.; Xiao, C.; Li, X. G.; Gao, X.; Synthesis of n-amyl acetate in a pilot-plant catalytic distillation column with seepage catalytic packing internal. Ind. Eng. Chem. Res., 2017, 56(44): 12726-12737.

(15)Li, X. G.; Wang, R.; Na, J.; Li, H.; Gao, X.; Reversible reaction-assisted intensification process for separating the azeotropic mixture of ethanediol and 1,2-butanediol: Reactants screening. Ind. Eng. Chem. Res., 2018, 57(2): 710-717.

(16) Li, H.; Zhao, Z.; Qin, J.; Li, X. G.; Gao, X.; Reversible reaction-assisted intensification process for separating the azeotropic mixture of ethanediol and 1,2-butanediol: Vapor-liquid equilibrium and economic evaluation. Ind. Eng. Chem. Res., 2018, 57(14): 5083-5092.

(17) Daniel, G.; Jobson, M.; Conceptual design of equilibrium reactor - reactive distillation flowsheets, Ind. Eng. Chem. Res., 2007, 46, 559-570.

(18) Wierschem, M.; Schlimper, S.; Heils, R.; Smirnova, I.; Kiss, A. A.; Skiborowski, M.; Lutze, P.; Pilot-scale validation of enzymatic reactive distillation for butyl butyrate production, Chem. Eng. J., 2017, 312, 106117.

(19) Heils, R.; Sont, A.; Bubenheim, P.; Liese, A.; Smirnova, I.; Integration of enzymatic catalysts in a reactive distillation column with structured packings, Ind. Eng. Chem. Res., 2012, 51(35), 11482-11489.

(20) Heils, R.; Jensen, J-H.; Wichert, S.; Behrens, N.; Fabuel-Ortega, M.; Liese, A.; Smirnova, I.; Enzymatic reactive distillation: Kinetic resolution of rac-2-pentanol with biocatalytic coatings on structured packings, Ind. Eng. Chem. Res., 2015, 54(38), 9458-9467.

(21) Wierschem, M.; Boll, S.; Lutze, P.; Górak, A.; Evaluation of the enzymatic reactive distillation for the production of chiral compounds, Chem. Ing. Tech., 2016, 88, 147-157.

(22) Kiss, A. A.; Jobson, M.; Taking reactive distillation to the next level of process intensification, Chem. Eng. Trans., 2018, 69, 553-558.

(23)Lutze, P.; Gorak, A.; Reactive and membrane-assisted distillation: Recent developments and perspective, Chem. Eng. Res. Des., 2013, 91, 1978-1997.

(24) Werth, K.; Lutze, P.; Kiss, A. A.; Stankiewicz, A. I.; Stefanidis, G. D.; Górak, A.; A systematic investigation of microwave-assisted reactive distillation: Influence of microwaves on separation and reaction, Chem. Eng. Process., 2015, 93, 87-97.

(25) Wierschem, M.; Skiborowski, M.; Gorak, A.; Schmuhl, R.; Kiss, A. A.; Techno-economic evaluation of an ultrasound-assisted enzymatic reactive distillation process, Comput. Chem. Eng., 2017, 105, 123-131.

(26) Mueller, I.; Kenig, E. Y.; Reactive distillation in a dividing wall column: Rate-based modeling and simulation, Ind. Eng. Chem. Res., 2007, 46 (11), 3709-3719.

(27) Schröder, M.; Ehlers, C.; Fieg, G.; A comprehensive analysis on the reactive dividing-wall column, its minimum energy demand, and energy-saving potential, Chem. Eng. Technol., 2016, 39, 2323-2338.

(28) Weinfeld, J. A.; Owens, S. A.; Eldridge, R. B.; Reactive dividing wall columns: A comprehensive review, Chem. Eng. Process., 2018, 123, 20-33.

(29) Sander, S.; Flisch C., Geissler, E.; Schoenmakers, H.; Ryll, O..; Hasse, H..; Methyl acetate hydrolysis in a reactive divided wall column, Chem. Eng. Res. Des., 2007, 85, 149-154.

(30) An, D.; Cai, W.; Xia, M.; Zhang, X.; Wang, F.; Design and control of reactive dividing-wall column for the production of methyl acetate, Chem. Eng. Process., 2015, 92, 45-60.

(31) Hernández, S.; Sandoval-Vergara, R.; Barroso-Muñoz, F. O.; Murrieta-Dueñas, R.; Hernández-Escoto, H.; Segovia-Hernández, J. G.; Rico-Ramirez, V.; Reactive dividing wall distillation columns: Simulation and implementation in a pilot plant, Chem. Eng. Process., 2009, 48, 250-258. 
(32) Delgado-Delgado, R.; Hernández, S.; Barroso-Muñoz, F. O.; Segovia-Hernández, J. G.; Castro-Montoya, A. J.; From simulation studies to experimental tests in a reactive dividing wall distillation column, Chem. Eng. Res. Des., 2012, 90, 855-862.

(33) Kiss, A. A.; Suszwalak, D. J-P. C.; Innovative dimethyl ether synthesis in a reactive dividing-wall column, Comput. Chem. Eng., 2012, 38, 74-81.

(34) Kiss, A. A.; Segovia-Hernandez, J. G.; Bildea, C. S.; Miranda-Galindo, E. Y.; Hernandez, S.; Reactive DWC leading the way to FAME and fortune, Fuel, 2012, 95, 352-359.

(35) Ignat, R. M.; Kiss, A. A.; Optimal design, dynamics and control of a reactive DWC for biodiesel production, Chem. Eng. Res. Des., 2013, 91, 1760-1767.

(36) Kiss, A. A.; Process intensification technologies for biodiesel production - Reactive separation processes, Springer Briefs in Applied Sciences and Technology series, 2014.

(37)Zheng, L.; Cai, W.; Zhang, X.; Wang, Y.; Design and control of reactive dividing-wall column for the synthesis of diethyl carbonate, Chem. Eng. Process., 2017, 111, 127-140.

(38) Dai, X.; Ye, Q.; Yu, H.; Suo, X.; Li, R.; Design and control of dividing-wall column for the synthesis of npropyl propionate by reactive distillation, Ind. Eng. Chem. Res., 2015, 54(15), 3919-3932.

(39) Kiss, A. A.; Pragt, J. J.; van Strien, C. J. G.; Reactive dividing-wall columns - How to get more with less resources?, Chem. Eng. Comm., 2009, 196(11), 1366-1374.

(40) Kiss, A. A.; Bildea, C. S.; Revive your columns with cyclic distillation, Chem. Eng. Prog., 2015, 111(12), 21-27.

(41)Bildea, C. S.; Patrut, C.; Jorgensen, S. B.; Abildskov, J.; Kiss, A. A.; Cyclic distillation technology - A mini-review, J. Chem. Technol. Biot., 2016, 91, 1215-1223.

(42) Patrut, C.; Bildea, C. S.; Kiss, A. A.; Catalytic cyclic distillation - A novel process intensification approach in reactive separations, Chem. Eng. Process., 2014, 81, 1-12.

(43) Nakaiwa, M.; Huang, K.; Endo, A.; Ohmori, T.; Akiya, T.; Takamatsu, T.; Internally heat-integrated distillation columns: A review, Chem. Eng. Res. Des., 2003, 81, 162-177.

(44)Olujic, Z.; Fakhri, F.; De Rijke, A.; De Graauw, J.; Jansens, P. J.; Internal heat integration - The key to an energy-conserving distillation column, J. Chem. Technol. Biot., 2003, 78, 241-248.

(45) Kiss, A. A.; Olujic, Z.; A review on process intensification in internally heat-integrated distillation columns, Chem. Eng. Process., 2014, 86, 125-144.

(46) Gadalla, M. A.; Olujic, Z.; Jansens, P. J.; Jobson, M.; Smith, R.; Reducing CO2 emissions and energy consumption of heat-integrated distillation systems, Env. Sci. Technol., 2005, 39, 6860-6870.

(47) Kiss, A. A.; Flores Landaeta, S. J.; Infante Ferreira, C. A.; Towards energy efficient distillation technologies - Making the right choice, Energy, 2012, 47, 531-542.

(48) Pulido, J. L.; Sarmiento, M. P.; Garzon, D. M.; Hernandez, M. A.; Gonzalez, A. D.; Peralta-Ruiz, Y. Y.; Duran, M.; Energy study of Reactive-HiDIC simulation for ethyl acetate synthesis from acetic acid, Chem. Eng. Trans., 2017, 58, 547-552.

(49) Vanaki, A.; Eslamloueyan, R.; Steady-state simulation of a reactive internally heat integrated distillation column (R-HIDiC) for synthesis of tertiary-amyl methyl ether (TAME), Chem. Eng. Process., 2012, 52, 2127.

(50) Gao, X.; Wang, F. Z.; Li, X. G.; Li, H.; Heat-integrated reactive distillation process for TAME synthesis. Sep. Purif. Technol., 2014, 132, 468-478.

(51)Leon-Pulido, J. L.; Martinez Arias, E. L.; Wolf Maciel, M. R.; Maciel Filho, R.; Heat integrated reactive distillation column (r-HIDiC): Implementing a new technology distillation, Chem. Eng. Trans., 2011, 24, 1303-1308.

(52) Mali, S. V.; Jana, A. K.; A partially heat integrated reactive distillation: Feasibility and analysis, Sep. Purif. Technol., 2009, 70, 136-139.

(53)Lin, Z.; An, W.; Xu, Y.; Zhu, J.; Conceptual design of an internally heat-integrated reactive distillation column based on thermodynamic and hydraulic analysis, Comput. Aided Chem. Eng., 2015, 37, 1451-1456.

(54) Cortes Garcia, G. E.; van der Schaaf, J.; Kiss, A. A.; A review on process intensification in HiGee 
distillation, J. Chem. Technol. Biot., 2017, 92, 1136-1156.

(55) Gudena, K.; Min, T. H.; Rangaiah, G. P.; Modeling and analysis of novel reactive HiGee distillation, Comput. Aided Chem. Eng., 2012, 31, 1201-1205.

(56) Gudena, K.; Rangaiah, G. P.; Samavedham, L.; Modeling and optimization of reactive HiGee strippermembrane process for methyl lactate hydrolysis, Ind. Eng. Chem. Res., 2013, 52, 7795-7802.

(57) Gudena, K.; Rangaiah, G. P.; Lakshminarayanan, S.; Modeling and analysis of solid catalyzed reactive HiGee stripping, Chem. Eng. Sci., 2012, 80, 242-252.

(58) Shi, Q.; Zhang, P.; Chu, G.; Chen, J.; A new high gravity catalytic reactive distillation process for n-butyl acetate synthesis, J. Beijing Univ. Chem. Technol., 2011, 38, 5-9.

(59)Chen, Y. H.; Huang, Y. H.; Lin, R. H.; Shang, N. C.; Chang, C. Y.; Chang, C. C.; Chiang, P. C.; Hu, C. Y.; Biodiesel production in a rotating packed bed using $\mathrm{K} / \gamma-\mathrm{Al} 2 \mathrm{O} 3$ solid catalyst. J. Taiwan Inst. Chem. Eng., 2011, 42, 937-944.

(60) Von Scala, C.; Moritz, P.; Fässler, P.; Process for the continuous production of fatty acid esters via reactive distillation, Chimia, 2003, 57, 799-801.

(61) Steinigeweg, S.; Gmehling, J.; Transesterification processes by combination of reactive distillation and pervaporation, Chem. Eng. Process., 2004, 43, 447-456.

(62) Aiouache, F.; Goto, S.; Reactive distillation-pervaporation hybrid column for tert-amyl alcohol etherification with ethanol, Chem. Eng. Sci., 2003, 58, 2465-2477.

(63) Buchaly, C.; Kreis, P.; Górak, A.; Hybrid separation processes - Combination of reactive distillation with membrane separation, Proceedings of the European Congress of Chemical Engineering (ECCE-6), Copenhagen, 16-20 September 2007.

(64)Lv, B.; Liu, G.; Dong, X.; Wei, W.; Jin, W.; Novel reactive distillation-pervaporation coupled process for ethyl acetate production with water removal from reboiler and acetic acid recycle, Ind. Eng. Chem. Res., 2012, 51, 8079-8086.

(65) Holtbruegge, J.; Wierschem, M.; Lutze, P.; Synthesis of dimethyl carbonate and propylene glycol in a membrane-assisted reactive distillation process: Pilot-scale experiments, modeling and process analysis, Chem. Eng. Process., 2014, 84, 54-70.

(66) Kiss, A. A.; Kattan Readi, O. M.; An industrial perspective on membrane distillation processes, J. Chem. Technol. Biot., 2018, 93, 2047-2055.

(67) Gao, X.; Study on catalytic reactive distillation process intensified by microwave irradiation, PhD Thesis. Tianjin University, Tianjin, 2011.

(68) Gao, X.; Li, X. G.; Zhang, J. S.; Sun, J. Y.; Li, H.; Influence of a microwave irradiation field on vaporliquid equilibrium. Chem. Eng. Sci., 2013, 90, 213-220.

(69) Li, H.; Cui, J. J.; Liu, J. H.; Li, X. G.; Gao, X.; Mechanism of the effects of microwave irradiation on the relative volatility of binary mixtures. AIChE J., 2017, 63(4), 1328-1337.

(70) Gao, X.; Liu, X. S.; Li, X. G.; Zhang, J. S.; Yang, Y.; Li, H.; Continuous microwave-assisted reactive distillation column: Pilot-scale experiments and model validation. Chem. Eng. Sci., 2018, 186, 251-264.

(71) Altman, E.; Stefanidis, G. D.; Gerven, T.; Stankiewicz, A. I.; Process intensification of reactive distillation for the synthesis of n-propyl propionate: The effects of microwave radiation on molecular separation and esterification reaction, Ind. Eng. Chem. Res., 2010, 49, 10287-10296.

(72)Ding, H.; Liu, M. C.; Gao, Y.; Qi, J.; Zhou, H.; Li, J.; Microwave reactive distillation process for production of ethyl acetate, Ind. Eng. Chem. Res., 2016, 55, 1590-1597.

(73) Kiss, A. A.; Geertman, R.; Wierschem, M.; Skiborowski, M.; Gielen, B.; Jordens, J.; John, J. J.; van Gerven, T.; Ultrasound-assisted emerging technologies for chemical processes, J. Chem. Technol. Biot., 2018, 93, 1219-1227.

(74) Baldea, M.; Edgar, T. F.; Stanley, B. L.; Kiss, A. A.; Modular manufacturing processes: Status, challenges, and opportunities, AIChE J., 2017, 63(10), 4262-4272. 